\title{
Nerve growth factor and Trk high affinity receptor (TrkA) gene expression in inflammatory bowel disease
}

F F di Mola, H Friess, Z W Zhu, A Koliopanos, T Bley, P Di Sebastiano, P Innocenti, A Zimmermann, $M$ W Büchler

\begin{abstract}
Background-Nerve growth factor (NGF), a target derived factor for survival and maintenance of peripheral and central neurones, has been implicated in several chronic inflammatory processes.

Aims-To analyse the concomitant presence of NGF and its high affinity receptor TrkA in patients undergoing surgery for Crohn's disease (CD) and ulcerative colitis (UC).

Patients-CD tissues were obtained from 33 patients and UC tissue samples from 12 patients undergoing surgery. Normal intestinal tissue samples were obtained from 30 individuals through an organ donor programme.
\end{abstract}

Methods-Expression of NGF and TrkA was studied by northern blot analysis. Using in situ hybridisation and immunohistochemistry, the respective mRNA moieties and proteins were localised. Western blot analysis was used to confirm the specificity of NGF and TrkA antibodies.

Results-In CD, NGF mRNA was increased in $60 \%(2.4-f o l d ; p<0.01)$ and TrkA mRNA in $54 \%(1.3$-fold; $p<0.05)$ of samples. In UC, NGF mRNA expression was enhanced in $58 \%(2.4-$ fold; $p<0.01)$ and TrkA mRNA expression in $50 \%$ (1.5-fold; $\mathbf{p}<0.05)$ of samples. In situ hybridisation showed that NGF and TrkA mRNA were often concomitantly present in polymorphonuclear-like cells of the lamina propria, in mast cells, and in a few ganglia of Auerbach's plexus and Meissner's plexus. Immunohistochemistry revealed that lamina propria cells and inflammatory cells (mainly mast cells) were NGF and TrkA immunopositive. NGF was also present in Meissner's plexus (especially in CD) and TrkA in enteric glia surrounding intestinal ganglia.

Conclusions-The concomitant enhanced expression of NGF and its receptor suggests activation of this pathway in chronic inflammation in $C D$ and UC. The presence of NGF and TrkA in both neural and non-neural structures in $C D$ and $U C$ supports the hypothesis that neuroimmune interactions occur and are activated in both disorders.

(Gut 2000;46:670-678)

Keywords: Crohn's disease; ulcerative colitis; inflammatory bowel disease; neuroimmune interaction; nerve growth factor; TrkA
Inflammatory bowel disease (IBD) comprises primarily two disease states: Crohn's disease (CD) and ulcerative colitis (UC). Recent neurobiology studies have demonstrated involvement of the enteric nervous system during intestinal inflammation in humans and in different animal models. ${ }^{1-3}$. However, abnormalities of the enteric nervous system are a common finding in patients with IBD and were first postulated to have a role in its pathogenesis almost 50 years ago. ${ }^{4}$ They are more characteristic of CD than UC and include both proliferative and degenerative changes. In $\mathrm{CD}$, morphological changes in the innervation pattern consisting of widespread alterations of the gut autonomic nervous system have been described. These include hypertrophy of nerve plexus, hyperplasia of ganglion cells, and ultrastructural axonal degeneration, all summarised as "neuromatous hyperplasia". ${ }^{5}$ Similar but less evident alterations have been reported in the colonic myoenteric plexus of longstanding UC, also suggesting that nerve alterations may modulate the inflammatory response. ${ }^{57}$

The molecular mechanisms involved in chronic intestinal inflammation and in alterations of the enteric nervous system in IBD are unclear. However, there is increasing evidence for mediators participating in changes in the enteric nervous system in these disorders. Recent preliminary studies have demonstrated that neurotrophins - such as nerve growth factor (NGF), brain derived neurotrophic factor (BDNF) and neurotrophin-3 - are abundantly expressed in the inflamed colon of different animal models of IBD and in human CD and UC tissue samples. ${ }^{8-10}$ In addition, there is immunohistochemical evidence that nerve growth factor receptor is increased in CD although the antibody used was not well defined. ${ }^{11}$ Inasmuch as NGF may influence neural survival and the phenotype of different peripheral sensory and sympathetic nerves, these findings suggest a potential role for NGF and its receptor in the maintenance of the enteric nervous system and in changes which occur during intestinal inflammation. ${ }^{12} 13$

$\mathrm{NGF}$ is produced by a range of cell types in response to different cytokines. Interleukin $1 \beta$

Abbreviations used in this paper: NGF, nerve growth factor; CD, Crohn's disease; UC, ulcerative colitis; IBD, inflammatory bowel disease; BDNF, brain derived neurotrophic factor; PDGF, platelet derived growth factor; FGF, fibroblast growth factor; TNF- $\alpha$, tumour necrosis factor $\alpha ; \mathrm{EGF}$, epidermal growth factor; TGF, transforming growth factor; SP, substance $\mathrm{P}$; CGRP, calcitonin gene related peptide. 
induces NGF synthesis in smooth muscle cells while in fibroblasts NGF synthesis is increased in response to interleukin $1 \beta$, platelet derived growth factor (PDGF), acidic or basic fibroblast growth factor (FGF), tumour necrosis factor (TNF) $\alpha$, epidermal growth factor (EGF), and transforming growth factor (TGF) $-\alpha$ and $-\beta .{ }^{13}$ Furthermore, CD $4+\mathrm{T}$ lymphocytes and mast cells express NGF and its high affinity receptor $\operatorname{TrkA}$, suggesting a possible interaction between the immune and neural systems in chronic inflammation. ${ }^{13} 14$

NGF signalling is mediated via binding to high and low affinity receptors. The high affinity receptor is called TrkA and signalling is transmitted via an internal tyrosine-kinase domain. p75, the low affinity receptor of NGF, belongs to the $G$ protein receptor family and plays a minor role in signal transduction. A recent study demonstrated that the responsiveness of NGF may be conferred by a single interaction of NGF with TrkA. ${ }^{15}$ TrkA is present in dorsal root and peripheral ganglia cells of primary sensory nerves and is involved in signal transduction of noxious stimuli and tissue injury. Inflammation results in an increase in NGF levels. NGF may itself have cytokine-like functions; it can modify mast cell, macrophage, and $\mathrm{B}$ cell functions but may also activate TrkA located on sensory and sympathetic nerve fibres innervating the site of inflammation, thus modulating neuroimmune interactions. ${ }^{16}$

In this study our aim was to analyse and locate concomitant gene expression of NGF and its high affinity receptor TrkA in CD and UC to further evaluate their potential role in the pathophysiology of these complex diseases.

\section{Methods}

PATIENTS

Normal human intestinal tissue samples were obtained from 30 patients (11 females, 19 males; median age 48 years; range 15-55) through an organ donor programme in which other organs were taken for organ transplantation. CD tissues were obtained from 33 patients (15 females, 18 males; median age 40.7 years; range 16-70) undergoing elective partial intestinal resection as a result of complications of the disease. UC tissue samples were obtained from 12 patients (six females, six males; median age 40 years; range 18-61) undergoing surgery.

IBD was diagnosed and CD and UC phenotypes were defined according to standard diagnostic criteria. ${ }^{17}$ IBD tissue samples were taken only from the most affected tissue segments, identified macroscopically. A diagnosis of CD or UC was confirmed in all patients by histopathological analysis performed by two independent pathologists. In addition, patients were followed up in the outpatient clinic and the diagnosis was confirmed one year after surgery by clinical follow up.

In the case of $C D$, disease severity was assessed preoperatively according to the simple index of Crohn's disease activity (CDAI) described by Best and colleagues ${ }^{18}$ and the activity index (AI) described by Van Hess and colleagues. ${ }^{19}$ Both indices showed active disease in all patients.

TISSUE SAMPLING

Immediately on surgical removal, normal, CD, and UC tissue samples were fixed in Bouin's solution or paraformaldehyde for 12-24 hours and embedded in paraffin for histological analysis. Simultaneously, a randomly selected part of the resected tissue samples which was destined for RNA extraction was snap frozen in the operating room in liquid nitrogen and maintained at $-80^{\circ} \mathrm{C}$ until use. The studies were approved by the Human Subjects Committee of the University of Bern, Switzerland.

\section{PROBE SYNTHESIS}

The NGF cDNA probe consisted of a 313 base pair (bp) KspI/SpeI fragment of human NGF cDNA. The TrkA cDNA probe consisted of a $401 \mathrm{bp} \mathrm{SacI/KspI} \mathrm{fragment} \mathrm{of} \mathrm{human} \mathrm{TrkA}$ cDNA. The identity of the cDNA fragments was sequenced using the dye terminator method as reported previously (ABI 373A, Perkin Elmer Rot Kreuz, Switzerland). A $190 \mathrm{bp} \mathrm{BamHI/BamHI}$ fragment of mouse 7S cDNA that cross hybridises with human $7 \mathrm{~S}$ RNA was used to verify equivalent RNA loading in northern blot experiments. NGF and TrkA cDNA fragments were subcloned into the pGEM-T Easy as previously reported. ${ }^{20}$ The $7 \mathrm{~S}$ cDNA probe was subcloned into the pGEM 7ZF(+) vector (Promega, Biotechnology, Madison, Wisconsin, USA). ${ }^{20}$

For northern blot analysis the cDNA (7S) and cRNA (NGF and TrkA) probes were radioactively labelled with $\left[\alpha-{ }^{32} \mathrm{P}\right] \mathrm{dCTP}$ and $\left[\alpha-{ }^{32} \mathrm{P}\right]$ CTP, respectively (Du Pont Boston, Massachusetts, USA). For in situ hybridisation analysis, sense and antisense cRNA probes of NGF and TrkA were labelled with digoxigenin as reported previously. ${ }^{21}$

\section{NORTHERN BLOT ANALYSIS}

Following RNA extraction and gel electrophoresis, RNA was electrotransferred onto nylon membranes (Gene Screen, Du Pont, Boston, Massachusetts, USA) and cross linked by UV irradiation. The filters were then prehybridised, hybridised, and washed under conditions appropriate for ${ }^{32} \mathrm{P}$-labelled antisense cRNA riboprobes (NGF and TrkA) or cDNA probes (7S) as previously reported. ${ }^{21-23}$

Membranes were then exposed at $-80^{\circ} \mathrm{C}$ to Fuji $x$ ray films with intensifying screens and the intensity of the radiographic bands was quantified using a computerised video system and Image-Pro Plus 3.0 software (Media Cybernetics, Silver Spring, Maryland, USA). All membranes were rehybridised with the 7S cDNA probe to assess equivalent RNA loading as previously reported. ${ }^{23}$ Data are expressed as the ratio of the NGF and TrkA mRNA signals divided by the corresponding $7 \mathrm{~S}$ signals. ${ }^{22}{ }^{23}$

\section{IN SITU HYBRIDISATION}

In situ hybridisation was performed according to a modified version of the protocol described previously. ${ }^{21}$ Briefly, five consecutive tissue sections $(4 \mu \mathrm{m})$ of each tissue sample were 
A

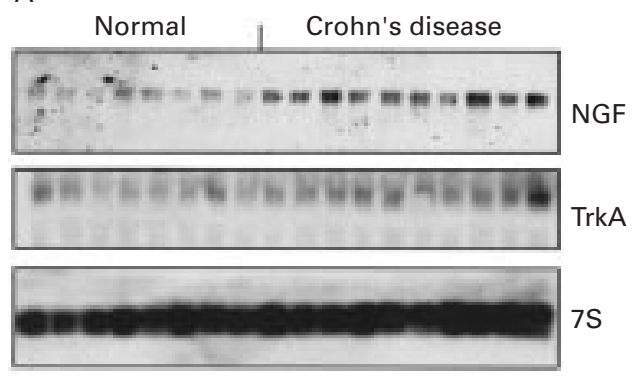

B

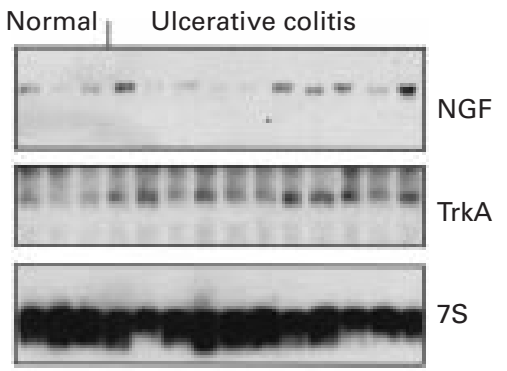

Figure 1 Northern blot analysis of NGF and TrkA $m R N A$ in normal intestine (lanes 1-8) compared with Crohn's disease (CD) (lanes 9-18) (A), and in normal intestine (lanes 1-3) compared with ulcerative colitis (UC) (lanes 4-13) (B). In many of the CD and UC samples enhanced NGF and TrkA mRNA expression was present compared with the normal controls. 7S RNA was used to assess equivalent $R N A$ loading.

permeabilised with proteinase $\mathrm{K}$ (Boehringer Mannheim, Mannheim, Germany), prehybridised, and then hybridised overnight at $65^{\circ} \mathrm{C}$ (NGF) and $66^{\circ} \mathrm{C}$ (TrkA). After hybridisation, excess probe was removed by washing in $2 \mathrm{X}$ $\mathrm{SSP} / 5 \mathrm{mM}$ EDTA and by RNase treatment at $37^{\circ} \mathrm{C}$ for 30 minutes. After washing for 20 minutes in $2 \mathrm{X} \mathrm{SSP} / 5 \mathrm{mM}$ EDTA at $65^{\circ} \mathrm{C}$ (NGF) and $68^{\circ} \mathrm{C}$ (TrkA) and for 20 minutes in $0.2 \mathrm{X} \mathrm{SSP} / 5 \mathrm{mM}$ EDTA under the same stringent conditions, the tissue sections were incubated with an antidigoxigenin antibody conjugated with alkaline phosphatase (Boehringer Mannheim, Mannheim, Germany). For the colour reaction, 5-bromo-4-chloro-3indolyl phosphate and nitroblue tetrazolium (Sigma, Buchs, Switzerland) were used.

Table 1 Summary of immunohistochemical and in situ hybridisation findings in Crohn's disease and ulcerative colitis

\begin{tabular}{|c|c|c|c|c|}
\hline & \multicolumn{2}{|c|}{ Immunohistochemistry } & \multicolumn{2}{|c|}{ In situ hybridisation } \\
\hline & $N G F$ & $\operatorname{Trk} A$ & $N G F$ & $\operatorname{Trk} A$ \\
\hline \multicolumn{5}{|l|}{ Crohn's disease } \\
\hline Lamina propria cells & +++ & ++ & +++ & ++ \\
\hline Auerbach plexus & $++/+++$ & - & $+1-$ & $+/-$ \\
\hline Meissner plexus & +++ & - & $+/-$ & $+/-$ \\
\hline Glia cells & - & $+/-$ & - & - \\
\hline Epithelial cells & - & - & $-/+$ & $-1+$ \\
\hline Mast cells & +++ & +++ & +++ & +++ \\
\hline \multicolumn{5}{|l|}{ Ulcerative colitis } \\
\hline Lamina propria cells & +++ & ++ & +++ & ++ \\
\hline Auerbach plexus & $++/+++$ & - & $+/-$ & $+/-$ \\
\hline Meissner plexus & $+/++$ & - & $+/-$ & $+/-$ \\
\hline Glia cells & - & $+/-$ & - & - \\
\hline Epithelial cells & - & - & $-/+$ & $-/+$ \\
\hline Mast cells & +++ & +++ & +++ & +++ \\
\hline
\end{tabular}

-, No signal; +, weak signal; ++, moderate signal; +++, intense signal.
IMMUNOHISTOCHEMISTRY

Paraffin embedded tissue sections $(2-4 \mu \mathrm{m}$ thick) were subjected to immunostaining using the streptavidin-peroxidase technique (Kirkegaard and Perry Laboratories, Gaithersburg, Maryland, USA). Five consecutive tissue sections for each tissue sample were submerged for 15 minutes in Tris buffered saline (TBS) (10 $\mathrm{mM}$ Tris HCI, $0.85 \% \mathrm{NaCI}, \mathrm{pH} 7.4$ ) containing $0.1 \%(\mathrm{vol} / \mathrm{vol})$ Triton $\mathrm{X}-100$ and then washed for five minutes in TBS solution as previously reported. ${ }^{19} 20$ Endogenous peroxidase activity was quenched by incubating the slides in methanol and methanol $/ 0.6 \%$ hydrogen peroxide followed by washings in methanol and TBS containing $0.1 \%$ bovine serum albumin..$^{23}$ The sections were then incubated for 30 minutes at $23^{\circ} \mathrm{C}$ with $10 \%$ normal goat serum and incubated overnight at $4^{\circ} \mathrm{C}$ with primary antibodies diluted in 10\% normal goat serum as follows: polyclonal anti-NGF (Santa Cruz Biotechnology, Santa Cruz, California, USA) (1:500 dilution) to detect the mature form of the NGF peptide; polyclonal anti-TrkA (TrkA immunoglobulin) (Santa Cruz Biotechnology) epitope corresponding to amino acids 763-777 mapping adjacent to the carboxy terminus of human Trk p140 (1:1000 dilution) and not cross reactive with Trk-B or Trk-C. Furthermore, a polyclonal anti-PGP 9.5 (Ultraclone Ltd, Isle of Wight, UK) (1:1000 dilution) antibody, which is well characterised as a panneuronal marker, was used. Bound antibody was detected with a biotinylated goat antirabbit IgG secondary antibody and a streptavidinperoxidase complex (Kirkegaard and Perry Laboratories) followed by incubation with diaminobenzidine tetrahydrochloride $(0.05 \%)$ as the substrate and counterstaining with Mayer's haematoxylin. To ensure antibody specificity, control slides were incubated either in the absence of primary antibody or with a non-specific IgG antibody. In both cases no immunostaining was detected. In addition, tissue sections obtained from normal intestine, $\mathrm{CD}$, and UC were processed with Giemsa staining to stain mast cells.

All slides were analysed by two independent observers blinded to patient status, followed by resolution of any differences by joint review and consultation with a third observer.

WESTERN BLOT ANALYSIS

Proteins were extracted from approximately $200 \mathrm{mg}$ of frozen tissues. Protein concentrations were measured with the micro BCA protein assay (Pierce, Rockford, Illinois, USA). From each sample $40 \mu \mathrm{g}$ of protein were separated on $12 \%$ (NGF) and $7 \%$ (TrkA) SDSpolyacrylamide gels and electroblotted onto nitrocellulose membranes. Nitrocellulose membranes were incubated in blocking solution ( $5 \%$ non-fat milk in $20 \mathrm{mM}$ Tris $\mathrm{HCl}, 150$ $\mathrm{mM} \mathrm{NaCl}, 0.1 \%$ Tween-20 (TBS-T)) followed by incubation with polyclonal anti-NGF antibodies (1:1600) (Santa Cruz Biotechnology) and anti-TrkA (1:10 000) (Santa Cruz Biotechnology) for one hour at room temperature. The membranes were then washed with TBS-T and incubated with a horseradish 
peroxidase conjugated donkey antirabbit IgG (1:1000 dilution) for 30 minutes at room temperature. Antibody detection was performed with an enhanced chemiluminescence reaction (ECL western blotting detection, Amersham Life Science, Amersham, UK).

COMPARISON OF MOLECULAR DATA WITH CLINICOPATHOLOGICAL FINDINGS

In the tissue samples with increased NGF and/or TrkA mRNA levels, molecular data were compared with clinicopathological parameters to determine if the increased gene expression in these samples was clinically significant. In this analysis, duration of disease, presence of fistulae and/or stenosis at the time of surgery, activity index, leucocyte level, and C-reactive protein
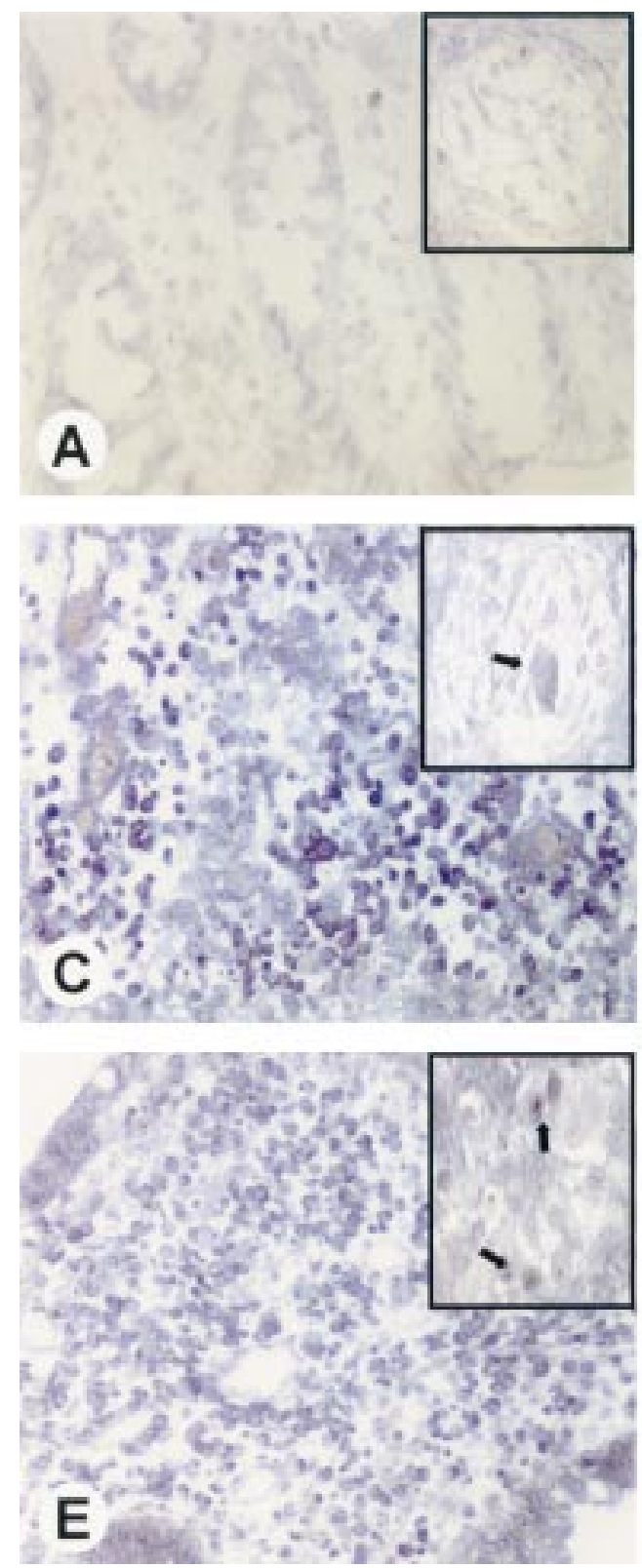

values were included. Because of the low number of tissue samples with increased expression of NGF and/or TrkA in patients with UC, this analysis was not performed.

STATISTICAL ANALYSIS

Results are expressed as median (range). For statistical analysis the Mann-Whitney test and Spearman test were used. Significance was defined as $\mathrm{p}<0.05$.

\section{Results}

NORTHERN BLOT ANALYSIS

Northern blot analysis of $20 \mu \mathrm{g}$ of total RNA was performed to determine the level of expression of NGF and TrkA mRNA in normal intestinal, CD, and UC tissue samples.
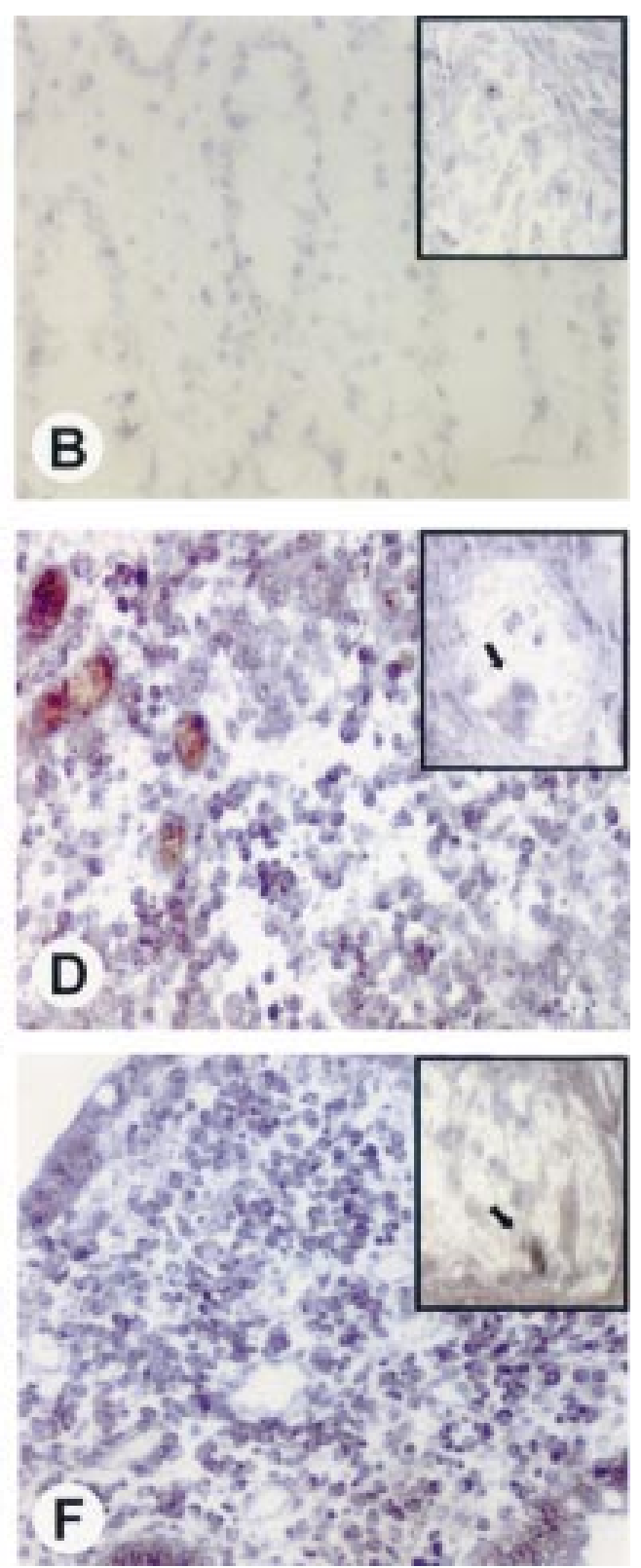

Figure 2 In situ hybridisation of $N G F(A, C, E)$ and Trk $A(B, D, F) m R N A$ expression in consecutive tissue sections of normal intestine $(A, B)$, and in samples from patients with Crohn's disease $(C D)(C, D)$ and ulcerative colitis (UC) (E, F). Strong NGF and TrkA mRNA signals often co-localised in polymorphonuclear-like cells of the lamina propria, especially close to the mucosal surface in both CD and UC. The inserts show ganglia of Auerbach's plexus with weak to moderate $m R N A$ signals for $N G F(A, C, E)$ and $\operatorname{Trk} A(B, D, F)$. Arrows indicate the positive signals. Original magnification $\times 200$; insert $\times 400$, 
Low levels of NGF (transcript size 1.3 kilobases) and TrkA (transcript size 3.2 kilobases) mRNA were observed in normal intestinal tissue samples (fig 1A, B). In $60 \%$ of the CD tissue samples there was a marked increase in NGF mRNA levels. TrkA mRNA levels were increased in $54 \%$ of the CD tissue samples. Densitometric analysis of the northern blots indicated that compared with the normal intestine there were 2.4- and 1.3-fold increases in NGF $(p<0.01)$ and TrkA $(p<0.05)$ mRNA levels, respectively, in these CD tissue samples (fig 1A).

In UC tissue samples, NGF mRNA expression was increased in $58 \%$ of samples and TrkA
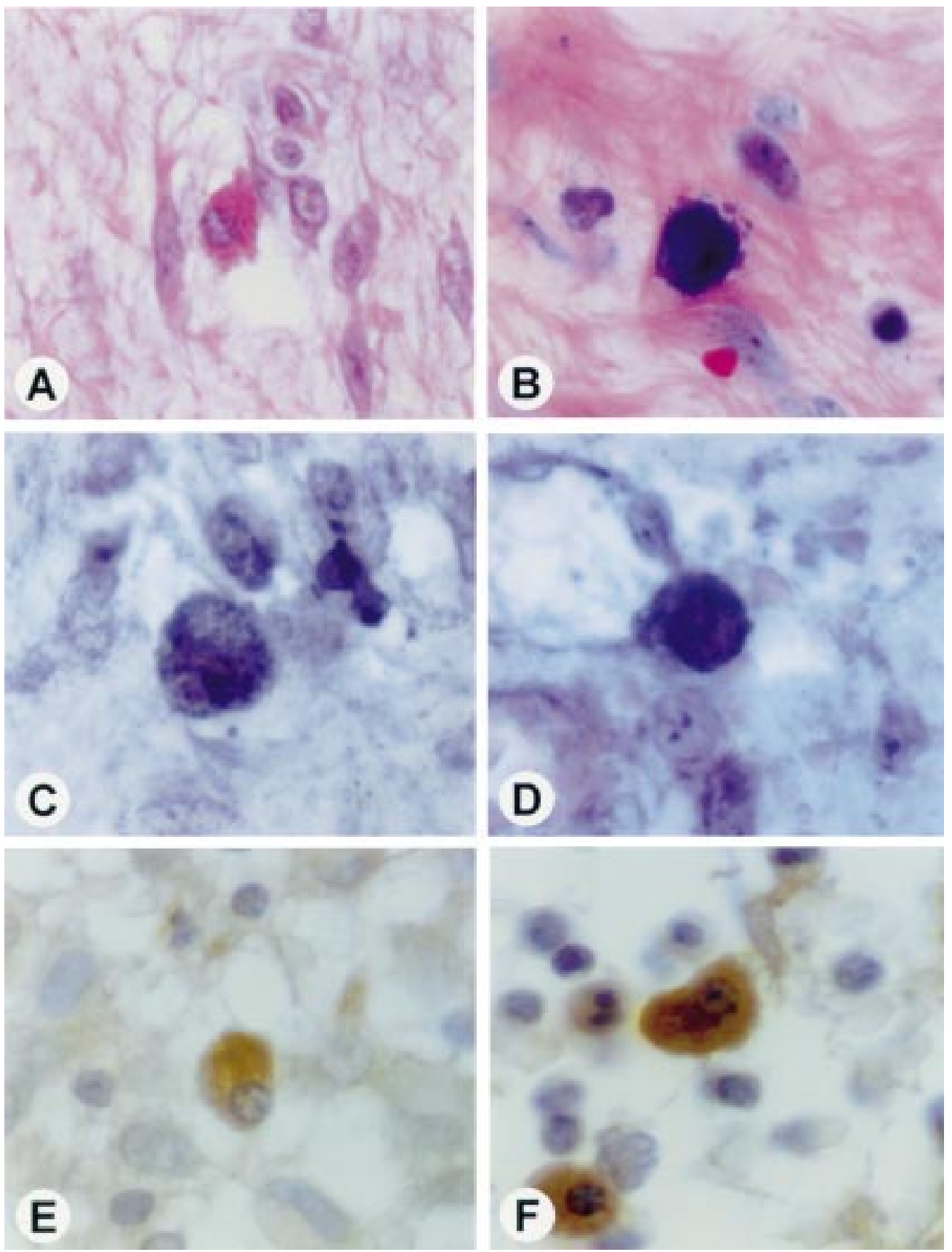

Figure 3 Haematoxylin and eosin staining (A), Giemsa staining (B), in situ hybridisation of NGF (C), and TrkA (D), and immunohistochemistry of NGF (E) and TrkA (F) in mast cells in tissue sections from patients with Crohn's disease $(C D)$. Moderate to strong in situ hybridisation signals $(C, D)$ and a comparable pattern of immunostaining $(E, F)$ of $N G F(C, E)$ and $\operatorname{Trk} A(D, F)$ were found in mast cells. Original magnification $\times 400$.

mRNA levels in $50 \%$ of samples. Densitometric analysis of the levels of expression in these UC samples revealed 2.4- and 1.5-fold increases in mRNA gene expression for NGF $(\mathrm{p}<0.01)$ and TrkA $(\mathrm{p}<0.05)$ (fig $1 \mathrm{~B})$.

In the subgroup of $\mathrm{CD}$ and UC tissue samples with increased mRNA expression, NGF and TrkA mRNA expression were concomitantly increased in $50 \%$ of CD and $71 \%$ of UC samples.

IN SITU HYBRIDISATION

In situ hybridisation was performed to determine the exact site of NGF and TrkA mRNA synthesis (table 1). Five consecutive tissue sec-
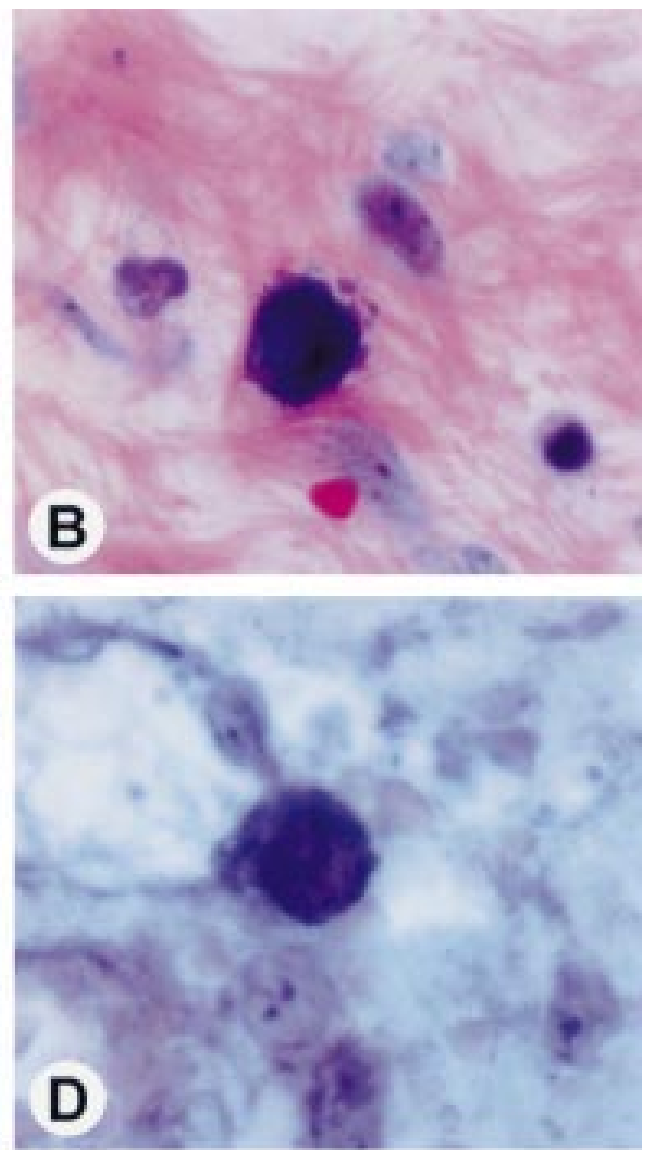

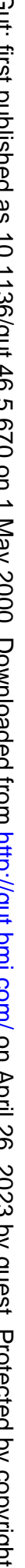


tions of each tissue sample from normal intestinal, CD, and UC tissue samples were always processed simultaneously.

In the normal intestine obtained from organ donors, weak NGF (fig 2A) and TrkA (fig 2B) mRNA signals were found. The signals were located in only very few lamina propria cells (mainly polymorphonuclear-like cells) and in some ganglia of Auerbach's intermuscular plexus (insert in fig 2A, B). Epithelial cells and muscle cells were devoid of NGF or TrkA mRNA signals. In contrast with the normal intestine, CD (fig 2C, D) and UC (fig $2 \mathrm{E}, \mathrm{F}$ ) tissue samples, which exhibited high levels of mRNA expression by northern blot analysis, also showed intense mRNA staining with in situ hybridisation. In both CD (fig 2C) and UC (fig 2E) tissue samples, NGF mRNA signals were present primarily in high rates in polymorphonuclear-like cells in the lamina propria and in mast cells (fig 3C) invading the whole intestinal wall. These findings were more evident in the area of severe damage and especially in the proximity of the mucosal surface (fig 2C, E). A few ganglia cells of the Meissner plexus and Auerbach's plexus exhibited weak to moderate NGF mRNA signals, particularly in CD (insert in fig 2C). Very weak NGF mRNA signals were present in the remaining intact epithelial cells of CD and UC samples (fig 2C, E). TrkA mRNA signals were often found in the same cell types that expressed NGF in both CD (fig 2D; fig 3D) and UC (fig $2 \mathrm{~F}$ ) tissue sections. In addition, weak to moderate TrkA signals were found in endothelial cells in both CD and UC tissue samples.

In situ hybridisation using DIG labelled sense probes corresponding to the antisense probes failed to produce signals (data not shown).

\section{IMMUNOHISTOCHEMISTRY}

Using consecutive sections, immunohistochemistry was performed to localise NGF and TrkA in CD and UC tissue samples (table 1). PGP 9.5 immunostaining was used to visualise the intrinsic nervous system by staining consecutive tissue sections of normal (fig 4A), CD (fig 4D), and UC (fig 4G) tissue samples.

In the normal intestine, weak NGF immunoreactivity was present in Auerbach's intermuscular plexus (insert in fig $4 \mathrm{~B}$, arrows) and very weak TrkA immunoreactivity (fig 4C) was located in the wall of the blood vessels and in nerve endings located in the villus. Ganglia cells were devoid of TrkA immunoreactivity
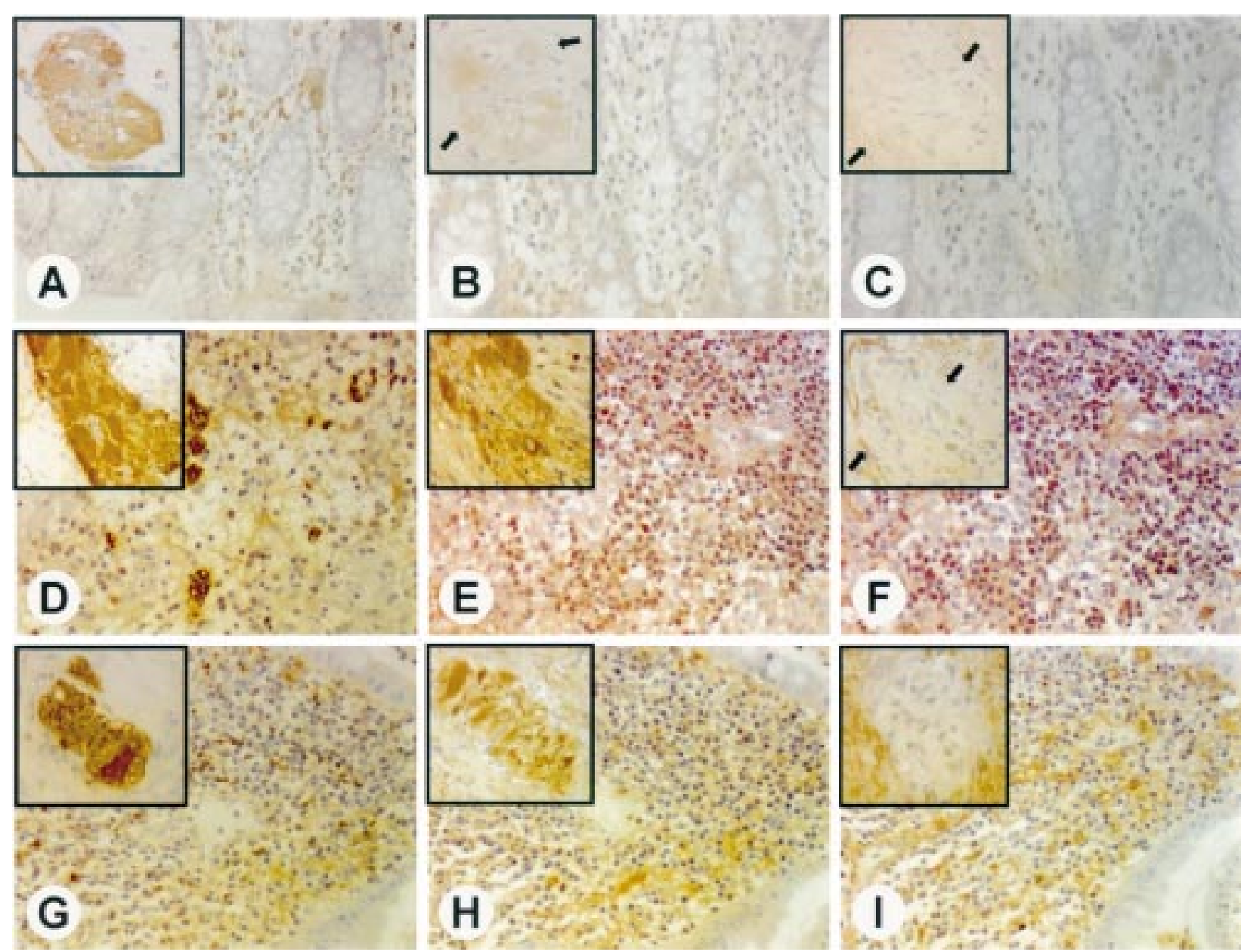

Figure 4 Immunohistochemical analysis of consecutive tissue sections for PGP $9.5(A, D, G), N G F(B, E, H)$, and TrkA (C, F, I) in the normal intestine $(A, B, C)$, in Crohn's disease $(C D)$ samples $(D, E, F)$ and in ulcerative colitis (UC) tissue samples ( $G, H, I)$. In contrast with the normal intestine (B, $C)$, in $C D(E, F)$ and $U C(H, I)$ intense concomitant immunostaining was found in the polymorphonuclear-like cells in the lamina propria close to the luminal surface. The inserts show NGF immunoreactive ganglia of Auerbach's plexus in the normal intestine (B, arrows indicate ganglia), $C D(E)$, and $U C(H)$. TrkA immunoreactivity was found mainly in the glia cells in the normal intestine (insert $C$, arrows), in CD (insert $F$, arrows), and in UC (insert I). The slides are counterstained with haematoxylin. Original magnification $\times 200$; insert $\times 400$. 


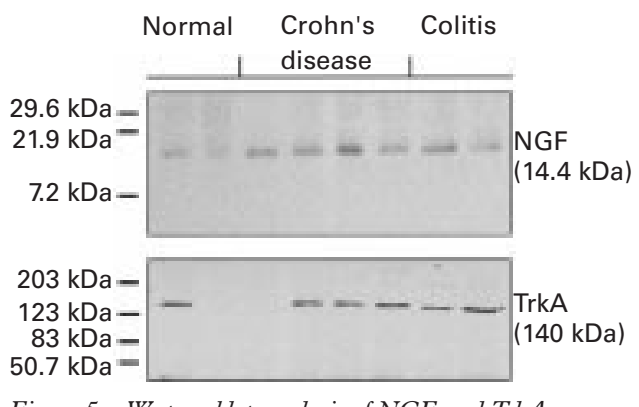

Figure 5 Western blot analysis of NGF and TrkA, indicating the specificity of the antibodies used. Lanes 1-2: normal intestine; lanes 3-6: Crohn's disease; and lanes 7-8: ulcerative colitis. The molecular weights of NGF and TrkA were approximately $14.4 \mathrm{kDa}$ and $140 \mathrm{kDa}$, respectively.

(insert in fig 4C, arrows). Furthermore, in normal intestine tissue samples, epithelial cells showed no immunoreactivity for either NGF or TrkA (fig 4B, C).

In contrast with the normal intestine, in general CD (fig $4 \mathrm{E}, \mathrm{F}$ ) and UC (fig $4 \mathrm{H}, \mathrm{I}$ ) tissue sections exhibited intense NGF (fig $4 \mathrm{E}, \mathrm{H}$ ) and TrkA (fig 4F, I) immunoreactivity. Particularly in CD tissues (insert in fig 4D), PGP 9.5 staining demonstrated an increased number and size of nerve fibres and ganglia. In both CD (fig 4E) and UC (fig 4H), intense NGF immunoreactivity was also found, mainly in polymorphonuclear-like cells in the lamina propria and in mast cells invading the intestinal wall (fig $3 \mathrm{E}$ ). In addition, in $\mathrm{CD}$ (insert in fig $4 \mathrm{E}$ ) and UC (insert in fig $4 \mathrm{H}$ ) intense NGF immunoreactivity was present in the Auerbach plexus and Meissner's plexus. These findings were more evident in CD tissue sections (insert in fig $4 \mathrm{E}$ ) where intrinsic ganglia were increased in size and number than in UC tissue samples. Intense TrkA immunoreactivity was detected in endothelial cells. In addition, TrkA immunoreactivity was found within nerve fibres located in the lamina propria of the remaining mucosa, particularly in neural fibre bundles and in the surrounding enteric glia of Meissner and Auerbach ganglia (insert in fig $4 \mathrm{~F}$, arrows). Inflammatory cells exhibited moderate to intense TrkA immunoreactivity in both CD (fig 4F) and UC (fig 4I) tissue sections. Most of the inflammatory cells invading the intestinal wall that demonstrated intense NGF and TrkA immunoreactivity were classified with Giemsa staining as mast cells in both CD (fig 3E, F) and UC (data not shown) tissues.

WESTERN BLOT ANALYSIS

To verify the specificity of NGF and TrkA antibodies, western blot analysis was performed in normal intestine, $\mathrm{CD}$, and UC tissue

Table 2 Clinicopathological comparison of expression of NGF, TrkA, and NGF/TrkA $m R N A$ levels in $C D$ patients

\begin{tabular}{llll}
\hline Clinicopathological feature & NGF $m R N A^{*}$ & $\operatorname{Trk} A m R N A^{*}$ & NGF/TrkA $m R N A^{*}$ \\
\hline Presence of fistulae and/or stenosis & $r=-0.6 ; \mathrm{p}<0.05$ & $\mathrm{NS}$ & $\mathrm{r}=-0.94 ; \mathrm{p}<0.01$ \\
Duration of disease (y) & NS & NS & NS \\
Activity index & NS & NS & NS \\
Leucocyte level & NS & NS & NS \\
C-reactive protein value & NS & NS & NS \\
\hline
\end{tabular}

^Densitometric value.

$r$, coefficient of correlation; NS, not statistically significant. samples (fig 5). Western blot analysis confirmed the specificity of NGF and TrkA antibodies. The NGF antibody detects an approximately $14.4 \mathrm{kDa}$ protein and the TrkA a $140 \mathrm{kDa}$ protein as reported previously (fig $5) .^{24}$

COMPARISON OF NGF AND TrKA GENE EXPRESSION WITH CLINICOPATHOLOGICAL CHARACTERISTICS

To determine if expression of NGF and/or TrkA in CD was clinically significant, the northern blot data were compared with some clinicopathological parameters (table 2).

In CD tissue samples there was a significant negative association between NGF mRNA levels and the presence of CD related complications (fistulae and/or stenosis) at the time of surgery $(r=-0.6 ; \mathrm{p}<0.05)$. However, there was no correlation between NGF mRNA levels and duration of disease, CD activity index, leucocyte level, or C-reactive protein levels.

Moreover, the negative relationship between the concomitant presence of NGF and TrkA mRNA and the presence of CD related complications was much stronger $(r=-0.94$; $\mathrm{p}<0.01$ ) than when the analysis was performed for NGF alone (table 2).

\section{Discussion}

In this study we found that expression of NGF and its signalling high affinity receptor TrkA were increased in the inflamed intestines of patients undergoing surgery for CD and UC compared with normal intestinal tissue samples. Many of the CD and UC tissue samples exhibited concomitant enhanced expression of NGF and TrkA mRNA, indicating activation of the NGF/TrkA signalling pathway in IBD. Using in situ hybridisation, we found that NGF and TrkA mRNA often co-localised in lamina propria cells, in inflammatory cells invading the intestinal wall (especially in CD), and in a few ganglia of the Auerbach plexus and Meissner's plexus. In addition, immunohistochemistry revealed intense NGF and TrkA immunoreactivity mainly in the Auerbach plexus and Meissner's plexus, which were often increased in number and size, ${ }^{56}$ and in the lamina propria cells-especially in those close to the luminal surface. In addition, in CD and UC, intense NGF and TrkA mRNA and protein signals were present in mast cells which had infiltrated the intestinal wall. Our data, demonstrating the presence of NGF and its high affinity receptor TrkA in both neural and non-neural structures in CD and UC, further support the hypothesis that the enteric nervous system is involved to some extent in the pathophysiology of IBD, and provide evidence for a "neuroimmune interaction" in these disorders.

Nerves in peripheral adult tissues are often considered to be a stable element with a low potential for remodelling and adaptation. Interestingly, Stead et al have demonstrated that inflammatory cells such as mast cells located in the lamina propria of the gut are in close contact with the enteric nerves thus demonstrating the anatomical connection between the enteric nerves and inflammatory cells. ${ }^{25}$ In addition, it has been reported that sensory 
nerve fibres exert protective effects on gastric mucosa in models of some experimentally induced gastric lesions, ${ }^{26}$ and experimentally induced colitis in rats is exacerbated if sensory nerves are disrupted by pretreatment with capsaicin. ${ }^{27}$ These observations led to the conclusion that nerves also have modulating functions in intestinal inflammation. In our study we found that in IBD, immune cells, especially mast cells infiltrating the intestinal wall in high numbers, expressed enhanced levels of NGF and TrkA. These findings are of interest because NGF released from these cells may bind to TrkA located in sensory and sympathetic nerves, thereby contributing to nerve activation and remodeling at the site of inflammation. Neural remodelling in chronic intestinal inflammation is characterised by initial axonal degeneration followed by nerve regeneration and sprouting, eventually resulting in successful re- or hyperinnervation. ${ }^{28}$ Inasmuch as several steps in wound healing and defence mechanisms are influenced by NGF, successful reinnervation may also be a critical aspect of the healing process and of the recovery of the mucosa in IBD. In fact, NGF released from mast cells in the proximity of the mucosal surface may act as a chemotactic factor for neutrophils ${ }^{29}$ and may activate plasminogen and the classical complement cascade ${ }^{30}$ thus inducing fibrinolysis which accelerates the wound healing process. ${ }^{31}$

In addition, our data indirectly suggest a critical role for NGF in the maintenance of mucosal integrity. In fact, in CD patients with high NGF mRNA expression we found a lower rate of intestinal fistulae and/or stenosis, and this association was even more evident in patients in whom concomitant enhanced expression of NGF and TrkA was present. This important aspect is supported by previous experimental data reporting a protective role of $\mathrm{NGF}$ and of the enteric nervous system in mucosal defence processes or in the induction of mucosal healing in these disorders. ${ }^{8-10}$ Furthermore, we need to emphasise that we did not analyse other "NGF related factors" such as BDNF and neurotrophin-3. Therefore, we cannot exclude a role for these factorsespecially in those patients who exhibited no enhanced NGF and/or TrkA mRNA levels-in the maintenance of surface integrity in the inflamed intestine, as was previously hypothesised in preliminary studies. ${ }^{8-10}$

The importance of neural structures in inflammation is also underlined in experimental studies where induction of inflammation by intraplantar injection of complete Freund's adjuvant results in local sensory hypersensitivity and upregulation of NGF but also of neuropeptides such as substance $\mathrm{P}$ (SP) and calcitonin gene related peptide (CGRP). ${ }^{32} \mathrm{~A}$ similar pattern of concomitant NGF and neurotransmitter upregulation was observed during the developmental period in rat sensory neurones where NGF regulates tachykinin gene expression and biosynthesis both in vivo and in vitro. ${ }^{33}$ In addition, involvement of different neuropeptides such as SP in the pathophysiology of IBD as modulators of immunological responses ${ }^{34}$ and as regulators of tissue remodelling is presently under discussion. ${ }^{35}$ In fact, recently Mantyh and colleagues $^{36}$ reported increased expression of the SP receptor in the enteric neurones of patients with $\mathrm{CD}$ and $\mathrm{UC}$, suggesting that $\mathrm{SP}$ is also involved in these disorders.

Interactions between nerves and inflammatory cells are not events restricted to chronic inflammation of the intestine. In chronic pancreatitis, an ongoing process of chronic inflammation in the pancreas (axonal damage associated with infiltration of inflammatory cells around enlarged pancreatic nerve bundles) has been reported, similar to damage in $\mathrm{CD}^{37-39}$ In chronic pancreatitis the intensity of the immune cell infiltration in the pancreas correlates with the presence and intensity of abdominal pain. ${ }^{40}$

In conclusion, our findings of the presence of NGF and TrkA in IBD in neural and inflammatory cells further support the hypothesis of a "neuroimmune interaction" in these inflammatory disorders in humans.

This study was supported by the Swiss National Fund's grant awarded to H Friess (SNF grant 32-49494).

1 Di Sebastiano P, Grossi L, di Mola FF, et al. SR140333, a substance P receptor antagonist, influences morphological and motor changes in rat experimental colitis. Dig Dis Sci 1999;44:439-44.

2 Fiocchi C. Intestinal inflammation: a complex interplay of immune and nonimmune cell interaction. Am $\mathcal{f}$ Physiol 1997;273:G769-75.

3 Di Sebastiano P, Fink T, di Mola FF, et al. Neuroimmune appendicitis. Lancet 1999; 354:461-6.

4 Davis DR, Dockerty MB, Mayo CW. The myoenteric plexus in regional enteritis:a study of the number of ganglion cells in the ileum of 24 cases. Surg Gynecol Obstet 1955;101:208-16.

5 Geboes K, Collins S. Structural abnormalities of the nervous system in Crohn's disease and ulcerative colitis. Neurogastroenterol Motil 1998;10:189-202.

6 Shanahan F. Enteric neuropathophysiology and inflammatory bowel disease. Neurogastroenterol Motil 1998;10:185-7.

7 Storsteen KA, Kernohan JW, Bargen JA. The myoenteric plexus in chronic ulcerative colitis. Surg Gynecol Obstet 1953;97:335-43.

8 Reinshagen M, Rohm H, Bonhagen I, et al. Expression of NGF prohormone in the lamina propria CD $4+$ lymphocytes repopulating scid mice. Gastroenterology 1997; 112:A1070

9 Reinshagen M, Rohm H, Lakshmanan J, et al. Expression of neurotrophin 3 prohormone in different animal models of ulcerative colitis and in human inflammatory bowel disease. Gastroenterology 1997;112:A1070

10 Rohm H, Reinshagen M, Schürmann G, et al. Gene expression of neurotrophins and their tyrosine kinase receptors in experimental colitis and inflammatory bowel disease. Gastroenterology 1997;112:A815.

11 Strobach RS, Ross AH, Markin RS, et al. Neural pattern in inflammatory bowel disease:an immunohistochemical survey. Mod Pathol 1990;3:488-93.

12 Kuroda $T$, Ueda M, Nakano $M$, et al. Altered production of nerve growth factor in aganglionic intestine. F Pediatr Surg 1994;29:288-92.

13 Levi-Montalcini R, Skapen SD, Dal Toso R, et al. Nerve growth factor: From neurotrophin to neurokine. Trends Neurosci 1996;19:514-20.

14 Lambiase A, Bracci-Laudiero L, Bonini S, et al. Human $\mathrm{CD} 4+$ clones produce and release nerve growth factor and express high affinity nerve growth factor receptor. F Allergy express high affinity nerve growth
Clin Immunol 1997;100:408-14.

15 Chao MV, Hampstead BL. p75 and Trk: a two-receptor system. Trends Neurosci 1995;18:321-6.

16 Ehrhard P, Erb P, Graumann U, et al. Expression of nerve growth factor and nerve growth factor receptor tyrosine kinase Trk in activated CD4-positive T-cell clones. Proc Natl Acad Sci USA 1993;90:10984-8.

17 Kirsner JB, Shorter RG, eds. Inflammatory bowel disease, 3rd edn. Philadelphia: Lea and Febiger, 1988

18 Best WR, Becktel JM, Singleton JW, et al. Development of a Crohn's disease activity index. Gastroenterology 1976;70: $439-44$

19 Van Hess PAM, Van Elteren PH, Van Leir HJJ, et al. An index of inflammatory activity in patients with Crohn's disease. Gut 1980;21:279-86.

20 Zhu ZW, Friess H, di Mola FF, et al. Nerve growth factor expression correlates with perineural invasion and pain in human pancreatic cancer. f Clin Oncol 1999;17:2419-28.

21 di Mola FF, Friess H, Martignoni M, et al. Connective tissue growth factor is a regulator of fibrosis in human chronic pancreatitis. Ann Surg 1999;230:63-71. 
22 Friess H, Yamanaka Y, Büchler $M$, et al. Enhanced expression of transforming growth factor- $\beta$ isoforms in pancreatic cancer correlates with decreased survival Gastroenterology 1993;105:1846-56.

23 di Mola FF, Friess H, Scheuren A, et al. Transforming growth factor- $\beta \mathrm{s}$ and their signaling receptors are coexpressed in Crohn's disease. Ann Surg 1999;229:67-75.

24 Kanaka-Gantenbein C, Tazi A, et al. In vivo presence of the high affinity nerve growth factor TrkA in the rat pancreas: differential localization during pancreatic development. Endocrinology 1995;136:761-9.

25 Stead RH, Dixon MF, Bramwell NH, et al. Mast cells are closely apposed to nerves in the human gastrointestinal mucosa. Gastroenterology 1989;97:575-85.

26 Holzer P, Pabst MA, Lippe Th. Intragastric capsaicin protects against aspirin-induced lesion formation and bleeding in the rat gastric mucosa. Gastroenterology 1989;96:1425-33.

27 Maggi CA, Meli A. The sensory-efferent function of capsaicin-sensitive sensory neurons. Gen Pharmacol 1988; 19:1-11.

28 Stead RH. Nerve remodeling during intestinal inflammation. Ann NY Acad Sci 1992;664:443-55.

29 Boyle MDP, Lawman MJP, Gee AP, et al. Nerve growth factor: a chemotactic factor for polymorphonuclear leukocytes in vivo. F Immunol 1985;135:564-8.

30 Koroly MJ, Young M. Nerve growth factor. Handb Exp Pharmacol 1981;57:249-54.

$31 \mathrm{Li}$ AKC, Koroly MJ, Schattenkerk ME, et al. Nerve growth factor: acceleration of rate of wound healing in mice. Proc Natl Acad Sci USA 1980;77:4379-82.
32 Woolf CJ, Safieh-Garaberdian B, Ma QP, et al. Nerve growth factor contributes to generation of inflammatory hypersensitivity. Neuroscience 1994;62:327-31.

33 Vedder H, Affolter H-U, Otten U. Nerve growth factor (NGF) regulates tachykinin gene expression and biosynthesis in rat sensory neurons during early postnatal development. Neuropeptides 1993;24:351-7.

34 Walsh JH, Dockray GJ. Gut peptides: biochemistry and physiology. New York: Raven Press, 1994:851-67.

35 Nilsson J, von Euler AM, Dalsgaard CJ. Stimulation of connective tissue cell growth by substance $\mathrm{P}$ and substance $\mathrm{K}$. Nature 1985;315:61-3.

36 Mantyh CR, Vigna SR, Bollinger RR, et al. Differential expression of substance $P$ receptors in patients with Crohn's disease and ulcerative colitis. Gastroenterology 1995;109:850-60.

37 Dvorak AM, Osage JE, Monahan RA, et al. Crohn's disease: transmission electron microscopic studies. III. Target issues. Proliferation of an injury to smooth muscle and autonomic nervous system. Hum Pathol 1980;11:620-34.

38 Bockman DE, Büchler M, Malfertheiner P, et al. Analysis of nerves in chronic pancreatitis. Gastroenterology 1988;94: 1459-69.

39 Friess H, Zhu ZW, di Mola FF, et al. Nerve growth factor and its high-affinity receptor in chronic pancreatitis. Ann Surg 1999;230:615-24.

$40 \mathrm{Di}$ Sebastiano P, Fink T, Weihe E, et al. Immune cell infiltration and growth-associated protein 43 expression correlate with pain in chronic pancreatitis. Gastroenterology 1997;112:1648-55. 